\title{
EXPERIMENTAL CHARACTERISATION OF CEMENT-BASED COMPOSITES WITH RICE HUSK
}

\author{
BEATRIZ MARQUES ${ }^{1,2}$, ANTÓNIO TADEU ${ }^{1,3}$, JOÃO ALMEIDA ${ }^{1,4} \&$ JULIETA ANTÓNIO $^{1,3}$ \\ ${ }^{1}$ Itecons - Institute of Research and Technological Development in Construction, Energy, Environment and \\ Sustainability, Portugal. \\ ${ }^{2}$ CERIS, Instituto Superior Técnico, University of Lisboa, Portugal. \\ ${ }^{3}$ ADAI- LAETA, Department of Civil Engineering, Faculty of Sciences and Technology, \\ University of Coimbra, Portugal. \\ ${ }^{4}$ Chemistry Centre, Department of Chemistry, University of Coimbra, Portugal.
}

\begin{abstract}
The construction sector has been adopting sustainability strategies to reduce the negative impacts of this industry. One of the most relevant strategies over the last years has been the incorporation of waste and natural materials. There has also been a more systematic demand for high-performance products with improved technical properties. Due to its durability and highly functional properties after hardening, concrete is one of the most commonly used building materials. Since there is a great volume of concrete being produced every year, studies are being developed to improve its sustainability through the incorporation of waste materials to substitute aggregates. In this context, the use of natural fibres and agricultural by-products such as rice husk offers important environmental advantages and it can be seen as an opportunity to recover a by-product with a high environmental disposable impact. At the same time, by partially replacing conventional aggregates with rice husk, the density of concrete can be lowered, contributing to greater economy in handling and transportation costs, improved thermal and acoustic performance and to an overall more sustainable material. This research aims to assess the potential of cement-based composite materials with rice husk through experimental characterisation tests and to address the main challenges regarding the incorporation of vegetable fibres in cementbased mixtures. The preliminary results obtained suggest that these cement-based composites will be adequate for thermal and acoustic performance of buildings, while contributing to generate waste recovery opportunities for the construction industry.

Keywords: Rice husk, Vegetable fibres, Cement composites, Sustainable materials.
\end{abstract}

\section{INTRODUCTION}

The construction sector has a significant social and economic impact in the European Union [1]. However, this industry is also responsible for negative impacts, such as depletion of natural resources, energy consumption and generation of waste that must be taken into account.

In this context, the development of innovative and low environmental impact building materials will benefit from waste recovery strategies, which may include the use of natural by-products and the increase of efficiency and performance.

The use of waste from different industries has been studied in different construction materials, such as mortars [2], concrete [3] and insulation materials [4]. Different types of waste have been studied: construction and demolition waste (CDW) [5], glass [6] and ceramics [7], among others.

Natural fibres and agricultural by-products offer important environmental advantages and is an opportunity to recover by-products with high environmental disposable impact. The incorporation of wood, hemp and rice straw and husk [8-10] in mortars have also been studied, to assess the beneficial impact on thermal and acoustic performance.

Rice is one of the most cultivated cereals in the world. Rice husk is a natural material with 1 to $4 \mathrm{~mm}$ in size [11] and it is considered a by-product from rice industry with high 
environmental impacts, considering both landfill or burning scenarios [12,13]. There are some examples of incorporation of rice husk into composite materials with hydraulic binders, where the benefits in terms of thermal insulation and density reduction are clear $[14,15]$. However, there are still important research opportunities for cement mixtures with rice husk in terms of acoustic properties, durability and hygrothermal behaviour, without changing its morphology and chemical structure.

The goal of this study is to perform an experimental characterisation of cement-based composite materials with rice husk, in order to develop an innovative and sustainable building solution. In this experimental work, the rice husk was collected at Baixo Mondego agricultural region in Portugal and used without any physical or chemical treatment.

\section{EXPERIMENTAL SETUP}

\subsection{Materials and samples}

Two types of rice husk cement-based composites were prepared: first, rice husk was added to the mixture without any preparation (Fig. 1a) and, in the second batch, rice husk was previously water-soaked (Fig. 1b). The goal is to access the influence of this preparation procedure on the behaviour of the composites.

The different composites were prepared with Portland cement type CEM II/B-L $42.5 \mathrm{R}$ $\left(350 \mathrm{~kg} / \mathrm{m}^{3}\right)$, natural rice husk $\left(90 \mathrm{~kg} / \mathrm{m}^{3}\right)$ and water, with a water-cement ratio of 0.40 .

For the characterization tests, small sized test specimens were prepared. The cement mixtures were prepared as cubic $\left(150 \times 150 \times 150 \mathrm{~mm}^{3}\right)$ and prismatic $\left(150 \times 150 \times 600 \mathrm{~mm}^{3}\right)$ test specimens, depending on the dimensions required for the different tests. After two days, the samples were placed in a climatic chamber at $(23 \pm 1)^{\circ} \mathrm{C}$ temperature and $(50 \pm 3) \%$ relative humidity to complete curing process up to 28 days.

\subsection{Methodology}

The mechanical, hygrothermal and acoustic characterization of the rice husk cement-based composites was performed through experimental test procedures described in this section.

This experimental work was carried out at the laboratory facilities of Itecons - Institute for Research and Technological Development for Construction Sciences, Energy, Environment and Sustainability, in Portugal.

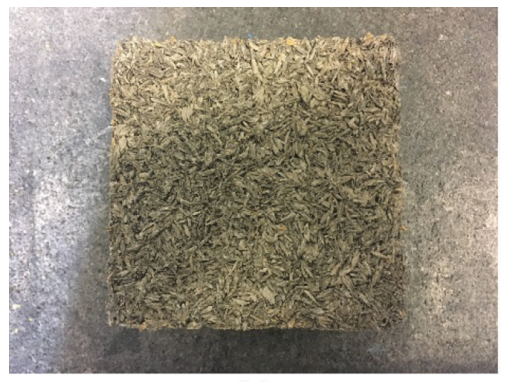

(a)

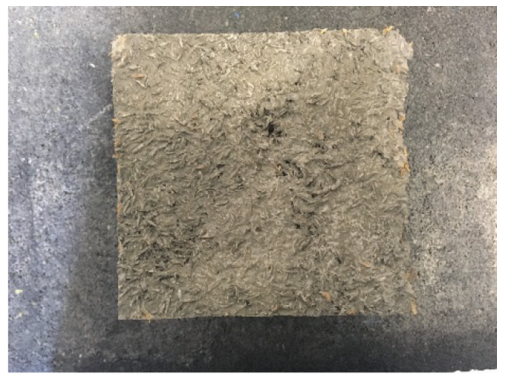

(b)

Figure 1: Rice husk cement-based composite samples: (a) RHC1 - with rice husk without any preparation; (b) RHC2 - with water-soaked rice husk. 


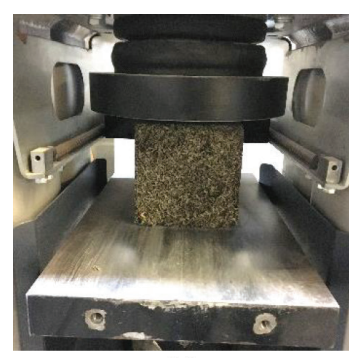

(a)

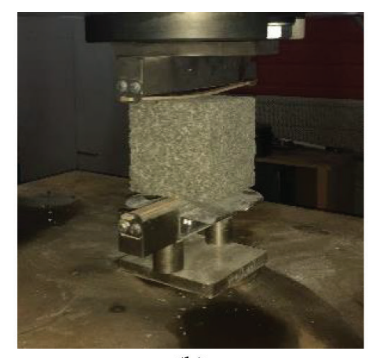

(b)

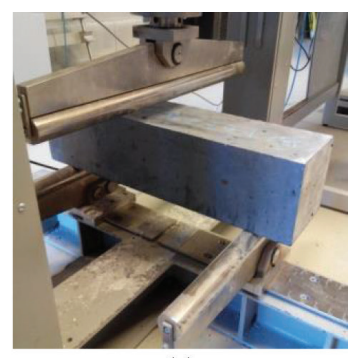

(c)

Figure 2: Mechanical characterization tests: (a) compressive strength; (b) tensile splitting strength; (c) flexural strength.

\subsubsection{Mechanical characterization tests}

The compressive strength tests were performed on cubic specimens, in compliance with NP EN 12390-3 [16]. This test was performed using an electromechanical universal testing machine, CONTROLS model 50-C56V2. This machine provides the load at failure, which is divided by the average cross-sectional area to obtain the compressive strength (Fig. 2a). The average of three test specimens from each batch gives the compressive strength.

The tensile splitting strength tests were conducted on cubic specimens, in accordance with NP EN 12390-6 [17]. This test was performed using an electromechanical universal testing machine, Shimadzu model UH-C2000KNI. The test specimens were placed in the centre of the testing machine and over packing strips. The loading of the test specimens by the packing strips causes the splitting of the cubes (Fig. 2b). The average of five test specimens from each batch gives the tensile splitting strength.

The flexural strength tests were carried out on prismatic test specimens, in compliance with NP EN 12390-5 [18]. This test was performed using the same universal testing machine as the compressive strength tests. The load is applied at the centre of the specimen length, and the maximum load is indicated by the machine, which is used to calculate the flexural strength (Fig. 2c). The average of three test specimens from each batch gives the flexural strength.

\subsubsection{Thermal characterization tests}

The thermal conductivity, $\lambda$ was found by the guarded hot plate method described in ISO 8302 [19], using a single specimen $\lambda$-Meter EP500 model from Lambda-Meßtechnik GmbH Dresden (Fig. 3a). The determination of thermal conductivity followed the test procedure described in EN 12664 [20].

For each mixture, three samples were sliced from the cubic specimens. Each specimen is, then, placed between the two large plates with $500 \times 500 \mathrm{~mm}$ dimension, aiming for a mean temperature of $23^{\circ} \mathrm{C}$ with a $15^{\circ} \mathrm{C}$ temperature difference between plates. Each sample is inserted within an insulation frame (Fig. 3b) to confirm the correct measurements within the measurement area of the guarded hot plate.

\subsubsection{Acoustic characterization tests}

The preliminary acoustic characterization of these composites was conducted on small sized samples by means of an impedance tube, in accordance to EN ISO 10534-2 [21], using 


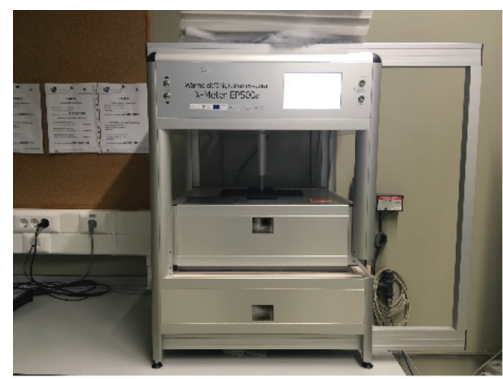

(a)

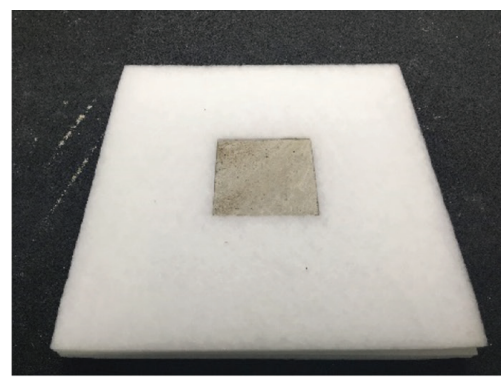

(b)

Figure 3: Thermal characterization tests: (a) $\lambda$-Meter EP500 model apparatus; (b) test sample inserted in the insulation frame.

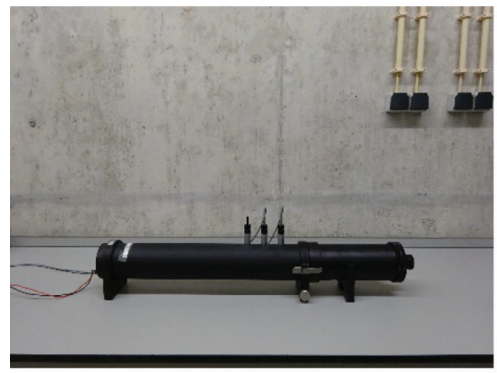

(a)

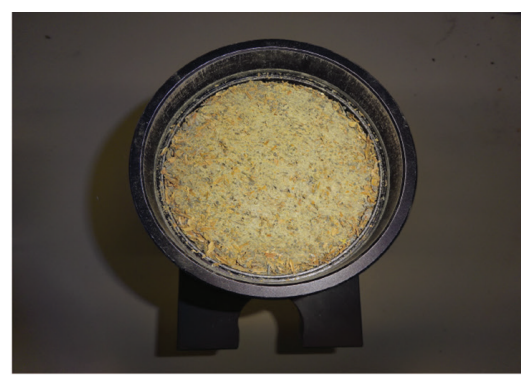

(b)

Figure 4: Acoustic characterization tests: (a) impedance tube for sound absorption tests (impedance tube prepared for the $100 \mathrm{~mm}$ diameter sample test); (b) $100 \mathrm{~mm}$ diameter test specimen inserted in the impedance tube.

29 and $100 \mathrm{~mm}$ diameter test specimens. The $100 \mathrm{~mm}$ diameter samples are used to determine the sound absorption coefficient in the frequency range from 100 to $1600 \mathrm{~Hz}$, while the $29 \mathrm{~mm}$ diameter samples in the frequency range from 500 to $6300 \mathrm{~Hz}$ (Fig. 4).

\section{RESULTS}

\subsection{Mechanical characterization tests}

The results of the mechanical characterization tests are presented in Table 1, with corresponding average apparent mass density results.

Natural fibres, such as rice husk, are known for their hygroscopic nature [22]. This ability to absorb moisture and water has a great influence on the curing process of the cement and, consequently, on the weight and mechanical properties of these composites.

As expected, the soaking process of rice husks before the preparation of the cement mixtures resulted in a mass increase of the samples. Additionally, there is also a significant increase on all the mechanical properties analysed in this study, especially regarding the compressive strength.

\subsection{Thermal characterization test}

The results of the thermal characterization tests are presented in Table 2. 
Table 1: Results of the mechanical tests.

\begin{tabular}{lcccc}
\hline & $\begin{array}{c}\text { Apparent mass } \\
\text { density } \\
{\left[\mathbf{k g} / \mathbf{m}^{3}\right]}\end{array}$ & $\begin{array}{c}\text { Compressive } \\
\text { strength } \\
{[\mathbf{M P a}]}\end{array}$ & $\begin{array}{c}\text { Tensile splitting } \\
\text { strength } \\
{[\mathbf{M P a}]}\end{array}$ & $\begin{array}{c}\text { Flexural } \\
\text { strength } \\
{[\mathrm{MPa}]}\end{array}$ \\
\hline $\mathrm{RHC} 1$ & $1070.1( \pm 165.8)$ & $1.76( \pm 0.83)$ & $0.42( \pm 0.07)$ & $0.60( \pm 0.01)$ \\
$\mathrm{RHC} 2$ & $1511.2( \pm 60.3)$ & $9.00( \pm 1.92)$ & $1.43( \pm 0.36)$ & $1.95( \pm 0.27)$ \\
\hline
\end{tabular}

Table 2: Results of the thermal conductivity tests.

\begin{tabular}{lcc}
\hline & $\begin{array}{c}\text { Apparent mass density } \\
{\left[\mathbf{k g} / \mathbf{m}^{3}\right]}\end{array}$ & $\begin{array}{c}\text { Thermal conductivity, } \boldsymbol{\lambda} \\
{[\mathbf{W} /(\mathbf{m} . \mathbf{K})]}\end{array}$ \\
\hline $\mathrm{RHC} 1$ & $1091.2( \pm 91.5)$ & $0.1226( \pm 0.0157)$ \\
$\mathrm{RHC} 2$ & $1311.4( \pm 14.6)$ & $0.3554( \pm 0.0210)$ \\
\hline
\end{tabular}

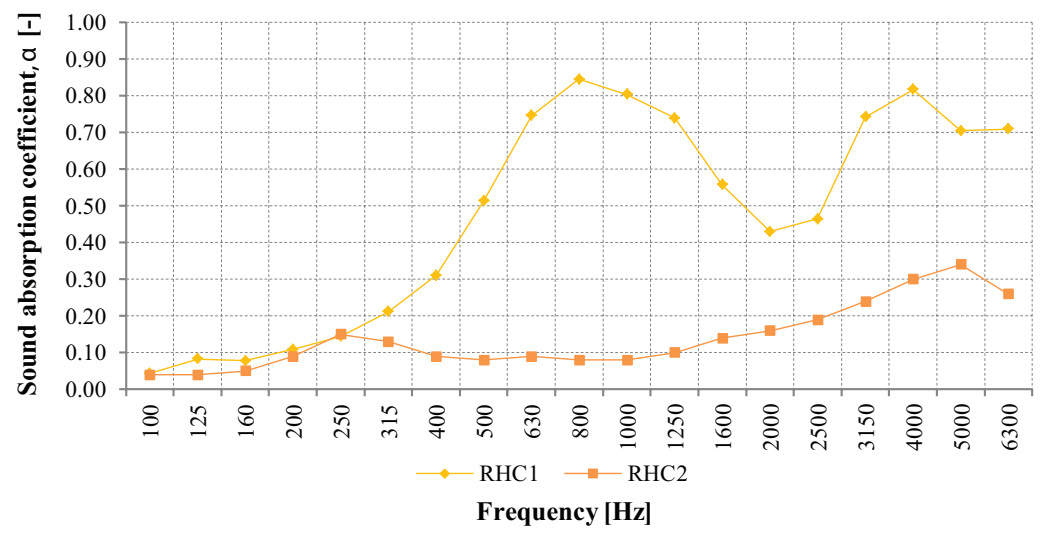

Figure 5: Sound absorption coefficient results.

An increase in the thermal conductivity results can be observed with the soaking process of rice husks before the preparation of the cement mixtures. This process allowed to produce more compact and dense samples. As a consequence, the test samples presented less voids and air gaps, resulting in a reduction on the insulation ability of these composites.

\subsection{Acoustic characterization test}

The results of the acoustic characterization tests are presented in Fig. 5.

From the RHC1 to RHC2, lower values of sound absorption are verified for all frequencies. The introduction of saturated rice husks may lead to a more homogeneous mixture with less pores and consequently a lower sound absorption capacity of these composites.

\section{CONCLUSIONS}

The presented results suggest that the preparation of rice husks has a significant influence on the performance of these cement-based composites. By soaking the rice husks before the introduction on the mixture, all water present on the cement paste will contribute to complete 
the curing process, reducing voids and air gaps, as the saturated rice husks will not absorb this added water. By performing this preparation of rice husks, unit weight and mechanical performance of the composites can be increased. On the other hand, by reducing the porosity, the thermal insulation performance of these composites is reduced, as well as the sound absorption behaviour. Considering these results, the preparation of this type of aggregates will depend on the functional requirements of the final building solutions.

Further research is required to validate the use of rice husk on cement-based composites, aiming for the development of building solutions. Considering the organic nature of these materials, additional durability tests are recommended.

\section{ACKNOWLEDGEMENTS}

This study was supported by the Portuguese Foundation for Science and Technology (FCT), under PhD grant PD/BD/113637/2015, under the Eco-Construction and Rehabilitation Programme. This work was also supported by the 'Bolsa de ignição' research grant within the InovC 2020 initiative, funded by the Centro 2020 Regional Operational Programme of Portugal 2020. The authors would also like to thank Farcimar company for preparing and providing the test specimens.

\section{REFERENCES}

[1] European Commission, The European construction sector: a global partner, Luxemburg, 2016.

[2] Silva, R.V., De Brito, J. \& Dhir, R.K., Performance of cementitious renderings and masonry mortars containing recycled aggregates from construction and demolition wastes, Construction and Building Materials. 105, pp. 400-415, 2016. doi:10.1016/j. conbuildmat.2015.12.171

[3] de Brito, J. \& Saikia, N., Recycled Aggregate in Concrete: Use of Industrial, Construction and Demolition Waste, Springer-Verlag London: London, 2013. doi:10.1007/9781-4471-4540-0.

[4] Asdrubali, F., D’Alessandro, F. \& Schiavoni, S., A review of unconventional sustainable building insulation materials, Sustainable Materials and Technologies, 4, pp. 1-17, 2015.

[5] Miranda, L.F.R. \& Selmo, S.M.S., CDW recycled aggregate renderings: Part II - Analysis of the effect of materials finer than $75 \mu \mathrm{m}$ under accelerated aging performance. Construction and Building Materials, 20, pp. 625-633, 2006. doi:10.1016/j.conbuildmat.2005.02.026

[6] Penacho, P., de Brito, J., Rosário Veiga, M., de Brito, J. \& Rosário Veiga, M., Physicomechanical and performance characterization of mortars incorporating fine glass waste aggregate. Cement and Concrete Composites. 50, pp. 47-59, 2014. doi:10.1016/j. cemconcomp.2014.02.007

[7] Matias, G., Faria, P. \& Torres, I., Lime mortars with ceramic wastes: Characterization of components and their influence on the mechanical behaviour. Construction and Building Materials. 73, pp. 523-534, 2014. doi:10.1016/j.conbuildmat.2014.09.108

[8] Chabannes, M., Garcia-Diaz, E., Clerc, L. \& Bénézet, J.-C., Studying the hardening and mechanical performances of rice husk and hemp-based building materials cured under natural and accelerated carbonation. Construction and Building Materials, 94, pp. 105-115, 2015. http://www.sciencedirect.com/science/article/pii/S095006181500714X

[9] Sassoni, E., Manzi, S., Motori, A., Montecchi, M., Canti, M., Novel sustainable hempbased composites for application in the building industry: Physical, thermal and mechanical characterization. Energy and Buildings, 77, pp. 219-226, 2014. doi:10.1016/j. enbuild.2014.03.033 
[10] Karade, S.R., Cement-bonded composites from lignocellulosic wastes. Construction and Building Materials, 24, pp. 1323-1330, 2010. doi:10.1016/j.conbuildmat.2010.02.003

[11] Bassyouni, M. \& Waheed U1 Hasan, S., The use of rice straw and husk fibers as reinforcements in composites. In Biofiber Reinforcements in Composite Materials, pp. 385-422, 2015. doi:http://dx.doi.org/10.1533/9781782421276.4.385

[12] Romasanta, R.R., Sander, B.O., Gaihre, Y.K., Alberto, M.C., Gummert, M., Quilty, J., Nguyen, V.H., Castalone, A.G., Balingbing, C., Sandro, J., Correa, T. \& Wassmann, R., How does burning of rice straw affect $\mathrm{CH} 4$ and $\mathrm{N} 2 \mathrm{O}$ emissions? A comparative experiment of different on-field straw management practices. Agriculture, Ecosystems and Environment, 239, pp. 143-153, 2017. doi:10.1016/j.agee.2016.12.042

[13] Bassyouni, M. \& Waheed U1 Hasan, S., Biofiber Reinforcements in Composite Materials, Elsevier, 2015. doi:10.1533/9781782421276.4.385

[14] Chabannes, M., Bénézet, J.-C., Clerc, L. \& Garcia-Diaz, E., Use of raw rice husk as natural aggregate in a lightweight insulating concrete: An innovative application. Construction and Building Materials, 70, pp. 428-438, 2014. doi:10.1016/j.conbuildmat.2014.07.025

[15] Sisman, C.B., Gezer, E. \& Kocaman, I., Effects of organic waste (rice husk) on the concrete properties for farm buildings. Bulgarian Journal of Agricultural Science, 17, pp. 40-48, 2011.

[16] Portuguese Standards, NP EN 12390-3 - Testing hardened concrete - Part 3: Compressive strength of test specimens, 2011.

[17] Portuguese Standards, NP EN 12390-6 - Testing hardened concrete - Part 6: Tensile splitting strength of test specimen, 2011.

[18] Portuguese Standards, NP EN 12390-5 - Testing hardened concrete - Part 5: Flexural strength of test specimens, 2009.

[19] ISO - International Organization for Standardization, ISO 8302 - Thermal insulation Determination of steady-state thermal resistance and related properties - Guarded hot plate apparatus, 1991.

[20] CEN - European Committee for Standardization, EN 12664 - Thermal performance of building materials and products. Determination of thermal resistance by means of guarded hot plate and heat flow meter methods. Dry and moist products of medium and low thermal resistance, 2001.

[21] CEN - European Committee for Standardization, EN ISO 10534-2 - Acoustics - Determination of sound absorption coefficient and impedance in impedance tubes - Part 2: Transfer-function method, 1998.

[22] Vo, L.T.T. \& Navard, P., Treatments of plant biomass for cementitious building materials - A review. Construction and Building Materials, 121, pp. 161-176, 2016. doi:10.1016/j.conbuildmat.2016.05.125 